\title{
A resiliência do enfermeiro no cuidado à criança que vivencia a terminalidade
}

The resilience of nurses in caring for children who experience terminality

La resiliencia de las enfermeras en el cuidado de niños que experimentan terminalidad

\section{Bruna Raiane Viana Andrade ${ }^{\mathrm{I}}$, Juliana Xavier Pinheiro da Cunha ${ }^{\mathrm{II}}$, Chrisne Santana Biondo ${ }^{\mathrm{III}}$}

Resumo: Objetivo: investigar a resiliência de enfermeiros no cuidado à criança que vivencia a terminalidade na terapia intensiva. Método: estudo qualitativo, com 12 enfermeiras das Unidades de Terapia Intensiva Pediátrica e Neonatal de dois hospitais no interior da Bahia. A coleta de dados ocorreu em abril e maio de 2019, utilizou-se a entrevista semiestruturada, analisada mediante Discurso do Sujeito Coletivo. Resultados: evidenciou-se a dificuldade das enfermeiras em lidar com a terminalidade infantil, referindo angústia e impotência, mais intensamente àquelas que são mães. A empatia e a espiritualidade se mostraram importantes no cuidado à criança terminal e no desenvolvimento da resiliência. Conclusão: faz-se necessário que a finitude seja enfrentada como curso natural da vida. Assim, deve-se ampliar estudos sobre a temática e que as instituições de ensino e laborais invistam em discussões sobre a terminalidade, para que as enfermeiras desenvolvam mecanismos de enfrentamento e de construção da resiliência no cuidado à criança.

Descritores: Enfermagem; Resiliência psicológica; Morte; Criança hospitalizada; Cuidado da Criança

\begin{abstract}
Objective: to investigate the resilience of nurses in caring for children experiencing terminality in intensive care. Method: a qualitative study conducted with 12 Pediatric and Neonatal Intensive Care Unit nurses of two hospitals in the countryside of Bahia. Data collection occurred in April and May 2019, and semi-structured interview was used, analyzed through Collective Subject Discourse. Results: it was evidenced the difficulty of nurses in dealing with child terminality, referring to anguish and impotence, more intensely to those who are mothers. Empathy and spirituality proved to be important in caring for terminally ill children and in developing resilience. Conclusion: it is necessary that finitude be faced as a natural course of life. Thus, studies on the theme should be expanded and educational and labor institutions invest in discussions about terminality so that nurses develop coping mechanisms and build resilience in child care.
\end{abstract}

Descriptors: Nursing; Resilience, Psychological; Death; Child, Hospitalized; Child Care

\footnotetext{
${ }^{\text {I }}$ Enfermeira graduada pela Universidade Federal da Bahia-UFBA. Vitória da Conquista, Bahia, Brasil. E-mail: brunarvandrade@hotmail.com Orcid: https://orcid.org/0000-0001-5839-2578

II Enfermeira. Doutoranda em epidemiologia pela Universidade Federal do Rio Grande do Sul-UFRGS. Professora assistente da Universidade Federal da Bahia-UFBA, Vitória da Conquista, Bahia, Brasil. E-mail: julianaxcunha@gmail.com Orcid: http://orcid.org/0000-0002-3752-206X

III Enfermeira. Doutoranda em ciências da saúde pela Universidade Estadual do Sudoeste da Bahia-UESB. Professora assistente da Universidade Federal da Bahia- UFBA, Vitória da Conquista, Bahia, Brasil. E-mail: tity_biondo_enf@hotmail.com Orcid: https://orcid.org/0000-0002-0583-5491
} 
A resiliência do enfermeiro no cuidado à criança que vivencia a terminalidade $\mid 2$

Resumen: Objetivo: investigar la resiliencia del enfermero en el cuidado de niños que experimentan terminalidad en cuidados intensivos. Método: estudio cualitativo, con 12 enfermeros de las Unidades de Cuidados Intensivos Pediátricos y Neonatales de dos hospitales del interior de Bahía. La recolección de datos se realizó en abril y mayo de 2019, se utilizó la entrevista semiestructurada, analizada a través del Discurso Colectivo del Sujeto. Resultados: se evidenció la dificultad de las enfermeras para afrontar la terminalidad infantil, referida a la angustia e impotencia, con mayor intensidad a las que son madres. La empatía y la espiritualidad demostraron ser importantes en el cuidado del niño terminal y en el desarrollo de la resiliencia. Conclusión: es necesario que la finitud se enfrente como un curso natural de la vida. Así, es necesario ampliar los estudios sobre el tema y que las instituciones educativas y laborales inviertan en discusiones sobre la terminalidad, para que las enfermeras desarrollen mecanismos de afrontamiento y construyan resiliencia en el cuidado infantil.

Descriptores: Enfermería; Resiliencia Psicológica; Muerte; Niño Hospitalizado; Cuidado del Niño

\section{Introdução}

A morte é um fenômeno complexo que desperta o temor de muitas pessoas, por revelar sentimentos como tristeza, perda e vazio, inclusive em profissionais da área da saúde, quando se trata do cuidado ao paciente terminal. A terminalidade pode fazer com que esses trabalhadores fiquem frente a frente com suas fragilidades, por despertar-lhes sentimentos de fracasso e impotência relacionados à assistência a quem enfrenta o fim da vida. ${ }^{1}$

Por vezes, não é possível prever o momento em que a morte se aproxima, porém, para algumas pessoas o fim da vida pode ser anunciado, a depender das condições clínicas em que se encontram: são os chamados pacientes terminais. A terminalidade pode ser caracterizada como o momento em que as possibilidades terapêuticas curativas se esgotam e o paciente não responde mais ao tratamento instituído, tornando o óbito previsível e inevitável. Nesse contexto, paciente, equipe de saúde e família se veem limitados e resistentes em reconhecer a finitude da vida. ${ }^{2}$

Quando a referência é infantil, a terminalidade permeia campos mais profundos, gerando sentimentos intensos e maior comoção, devido às expectativas empregadas ao infante e sua projeção para o futuro, frente à idealização de um ciclo de vida. Essas representações culturais interferem no cuidado prestado pelos enfermeiros à criança no fim da vida. ${ }^{3}$ Assim, o predomínio da cultura ocidental, com tendência a afastar a ideia de morte, o preparo 
3 | Andrade BRV, Cunha JXP, Biondo CS

profissional voltado para a restauração da saúde e a forte idealização de um futuro para a criança tornam difícil a aceitação da terminalidade pela equipe de enfermagem.

Nesse sentido, os enfermeiros que atuam em Unidades de Terapia Intensiva (UTI) infantil se deparam diariamente com a incerteza e o medo da morte no cuidado à criança terminal. Essas experiências causam sofrimento nos profissionais, que passam inclusive a questionar suas habilidades, sentindo-se, por vezes, frustrados e, por isso, tendem a lutar contra essa realidade iminente..$^{4-5}$ Isso reflete o processo de formação curricular, permeada por lacunas no ensino ao cuidado em terminalidade, haja vista que a formação está voltada à reparação da saúde, e durante a atuação dificilmente surgem espaços para se refletir e dialogar sobre a terminalidade infantil e a morte. ${ }^{1}$

O enfrentamento diz respeito aos esforços empregados para lidar ou, por vezes, mudar uma circunstância. Salienta-se que a forma de encarar o processo da morte baseia-se nos valores e significados individuais atribuídos. Desse modo, o padrão de cuidado recebido pela criança e sua família depende também da capacidade de enfrentamento do enfermeiro. ${ }^{6}$

A resiliência apresenta-se, então, como ferramenta de enfrentamento da terminalidade e possibilita o desenvolvimento de estratégias para que o profissional assista o sofrimento infantil. Apesar de não haver um consenso absoluto quanto ao seu conceito, a resiliência pode ser definida como a capacidade de enfrentar, se adaptar e superar adversidades; não significa a ausência de angústias, mas representa o autogerenciamento e a forma de lidar com situações que podem ser traumáticas. ${ }^{3-4}$

Diante do exposto, evidencia-se a importância de se aprofundarem estudos sobre a temática, visto que assuntos relacionados à terminalidade e seus desdobramentos, como a resiliência do enfermeiro que lida com a morte infantil, não são abordados de forma ampla durante a formação profissional. ${ }^{1}$ Além disso, a revisão de literatura, realizada nas bases de dados por meio dos descritores Enfermagem; Resiliência psicológica; Morte; Criança hospitalizada; e 
A resiliência do enfermeiro no cuidado à criança que vivencia a terminalidade $\mid 4$

Cuidado da Criança, demonstrou pesquisas incipientes, quando direcionadas à abordagem da terminalidade infantil com foco no enfermeiro, agregando, portanto, relevância a este estudo.

Frente a isso, busca-se responder à seguinte questão de pesquisa: Como se estabelece a resiliência de enfermeiros no cuidado à criança que vivencia a terminalidade na terapia intensiva? A fim de responder este questionamento, objetiva-se investigar a resiliência de enfermeiros no cuidado à criança que vivencia a terminalidade na terapia intensiva.

\section{Método}

Estudo descritivo, exploratório de abordagem qualitativa, realizado em dois hospitais da rede pública de uma cidade no interior da Bahia, nas UTIs Neonatal e Pediátrica. Um deles conta com UTI pediátrica e neonatal, sendo 5 e 10 leitos, respectivamente. O segundo possui apenas UTI neonatal, com 10 leitos. Os participantes da pesquisa obedeceram aos seguintes critérios de seleção: ser enfermeiro atuante em terapia intensiva infantil ou neonatal, por pelo menos seis meses, e que em algum momento tenha cuidado de criança em estado terminal. A escolha dos participantes ocorreu de forma não probabilística, por conveniência, delimitados pelo critério de saturação dos dados, ou seja, o número final de participantes foi determinado num ponto em que não houve novas informações e a redundância foi obtida. ${ }^{7}$

Assim, diante do universo total de 22 enfermeiros (13 UTI Neonatal e 9 UTI Pediátrica), inicialmente 15 foram convidados a participar deste estudo, dos quais 14 aceitaram, porém foram excluídos 2 profissionais que não se encaixavam nos critérios de seleção, por não possuírem o tempo mínimo de seis meses de atuação em Terapia Intensiva Infantil. Os demais enfermeiros não foram convidados, pois houve o alcance dos objetivos por saturação dos dados, resultando em um total de 12 participantes.

A coleta de dados se deu durante os meses de abril e maio de 2019, e consistiu na aplicação de uma entrevista semiestruturada contendo perguntas a fim de se estabelecer um 
5 | Andrade BRV, Cunha JXP, Biondo CS

perfil sociodemográfico dos entrevistados, além das seguintes questões: Por que você escolheu trabalhar com crianças que necessitam de suporte intensivo de vida? Como você se sente ao cuidar de crianças que vivenciam a terminalidade? Quais os desafios que você enfrenta no trabalho ao assistir crianças que vivenciam a terminalidade? Você já enfrentou alguma situação marcante em que se abalou ao prestar assistência a uma criança em estado terminal? Você recorreu a alguém? Que suporte e/ou estratégias você utilizou para enfrentamento? Quais as qualidades que você julga necessárias para trabalhar com crianças criticamente enfermas? Você se acha resiliente? Por quê?

As coletas ocorreram em local privativo, a fim de garantir privacidade aos participantes, após a assinatura do Termo de Consentimento Livre e Esclarecido. As entrevistas tiveram a média de 15 minutos de duração, foram gravadas em aparelho digital de áudio, posteriormente transcritas e analisadas pela técnica do Discurso do Sujeito Coletivo (DSC). ${ }^{8}$ Para fins de identificação dos participantes e garantia de anonimato, conferiu-se a letra E (de entrevistado), seguida do número correspondente à sequência das entrevistas.

O DSC foi escolhido por ser uma proposta de organização e tabulação de dados qualitativos de natureza verbal, que busca, a partir das ideias centrais ou das ancoragens identificadas no processo de análise, reunir o máximo de expressões dos sujeitos. Este método utiliza como figuras metodológicas: expressões-chave $(\mathrm{ECH})$, ideias centrais (IC), ancoragem (AC) e o discurso do sujeito coletivo (DSC). ${ }^{8}$

As ECH correspondem à fase de exploração e destaque de trechos do discurso que revelam a essência do depoimento. A partir das ECH são retiradas as IC, que descrevem de maneira mais sintética e precisa o sentido do discurso analisado. A AC é utilizada para enquadrar uma situação específica, sendo uma manifestação linguística de uma ideologia ou crença do sujeito autor do discurso. As IC e AC são então categorizadas e agrupadas de acordo ao sentido que apresentam. Esses elementos contribuíram para a construção do DSC, que é um 
A resiliência do enfermeiro no cuidado à criança que vivencia a terminalidade $\mid 6$

discurso único e coerente, regido na primeira pessoa do singular, com a finalidade de o "eu" falar em nome de uma coletividade. ${ }^{8}$

A pesquisa foi aprovada pelo Comitê de Ética e Pesquisa da Fundação Pública de Saúde de Vitória da Conquista, em 26/03/2019, com o parecer número: 3.223 .720 e Certificado de Apresentação para Apreciação Ética 07992919.1.0000.8089, conforme resolução nº 466/2012 do Conselho Nacional de Saúde.

\section{Resultados}

Com relação à análise sociodemográfica, todos os participantes foram do sexo feminino, com idades compreendidas entre 31 e 41 anos, com média de 35,5 anos, 41,7\% (n=05) solteiras, 33,3\% $(\mathrm{n}=04)$ casadas, $16,7 \%(\mathrm{n}=02)$ em união estável e $8,3 \%(\mathrm{n}=01)$ divorciadas, $58,3 \%(\mathrm{n}=07)$ possuem filhos e $83,3 \%(n=10)$ professam religião de origem cristã. Com relação à UTI, 83,3\% (n=10) das entrevistadas atuam na neonatal e $16,7 \%(\mathrm{n}=02)$ na pediátrica. As participantes possuem uma média de 10,5 anos de formação acadêmica e de seis anos de atuação em terapia intensiva infantil.

A análise das informações colhidas por meio das entrevistas possibilitou a identificação de três IC: (1) Desafios e sentimentos envolvidos na assistência à criança terminal, (2) Empatia para assistir a criança que enfrenta a terminalidade, (3) Construção da resiliência para o cuidado à criança no fim da vida.

\section{IC 1: Desafios e sentimentos envolvidos na assistência à criança terminal}

O cuidado à criança terminal envolve processos que desafiam a atuação prática das enfermeiras e também as suas emoções, por vezes gerando sentimentos de tristeza, frustação e impotência. Isso reflete a dificuldade que essas profissionais apresentam em aceitar a terminalidade e a obrigação a que se impõem de lutar pela cura, independentemente do prognóstico do paciente, como pode ser evidenciado no discurso a seguir. 
É difícil aceitar a terminalidade, é sofrido e muitas vezes a gente trabalha com o coração apertado. Mesmo depois de anos, não me acostumei e acho que não devo me acostumar a ver uma criança morrer, costumo dizer que isso não podia acontecer com criança, elas deveriam ser protegidas. $A$ gente se sente frustrado, triste e impotente por saber que a criança não vai sair daquele quadro, é como se a gente não pudesse oferecer tratamento, foge do nosso controle e não sabemos bem como lidar. Às vezes, mesmo em cuidados paliativos, a gente fica com receio de não realizar certas condutas porque esse "não podemos fazer nada” não entra na cabeça, não faz sentido. Ainda mais trabalhando em UTI, a gente está lá para lutar contra aquela situação adversa, não tem como pensar que está fazendo o bem sem interferir em nada. É difícil. E quando você tem filhos fica pior, você acaba tendo um olhar diferenciado. Quando eu não tinha, já sentia muito, depois, acredito que intensificou a sensibilidade. (DSC 1)

\section{IC 2: Empatia para assistir a criança que enfrenta a terminalidade}

As enfermeiras referem que a assistência voltada ao menor que vivencia a terminalidade precisa ser empática, o que não se resume apenas ao olhar sensível para com o paciente, mas também à sua família. O envolvimento com a história de vida da criança faz com que as profissionais acolham os familiares e os auxiliem no processo de terminalidade. No entanto, estes fatores podem interferir no emocional das enfermeiras, e encontrar o equilíbrio entre a rotina técnica de cuidados e o desenvolvimento de atitudes empáticas se mostra um desafio, como demonstrado no DSC apresentado a seguir.

A gente que trabalha com criança sabe que não é só o paciente, tem um contexto, um envolvimento familiar e acaba acontecendo um compartilhamento, a gente sente e vive aquele momento junto com a família porque se apega à história dos pais e o que eles passaram para ter aquela criança. Por isso eu sempre tento conversar, ficar mais próxima e ajudar a família a trabalhar essa partida que é extremamente difícil. A partir do momento que eu vejo uma criança morrendo, percebo o sofrimento dos pais e eu fico numa boa, já deixei de ser humano. Eu tento ser o mais humano possível, me colocar no lugar e perceber o quanto o outro pode estar sofrendo, não sendo melancólico ou duro demais, tento 
A resiliência do enfermeiro no cuidado à criança que vivencia a terminalidade $\mid 8$

encontrar um meio termo. Tem profissional que trabalha no mecânico e você precisa ser empático e pensar que aquele paciente poderia ser um filho seu, porque quando você olha assim, você é mais atenciosa, carinhosa e cuidadosa. Precisa ser sensível, e nessas situações de terminalidade a sensibilidade tem um impacto infinitamente maior, e esse é um desafio, não deixar virar rotina a questão da perda. (DSC 2)

\section{IC 3: Construção da resiliência para o cuidado à criança no fim da vida}

A partir das vivências profissionais relacionadas à terminalidade infantil, muitas enfermeiras desenvolvem estratégias para o enfrentamento e construção da resiliência, a fim de obterem um equilíbrio emocional frente à morte da criança. Elas encontram no apoio de colegas de trabalho e na espiritualidade suporte para desenvolverem a resiliência, o que resulta tanto em crescimento pessoal quanto profissional, como demonstrado pelo DSC apresentado a seguir.

A equipe de enfermagem está no trato direto ao paciente, por isso tem que tentar ter um equilibrio emocional para cuidar e amenizar o sofrimento. Às vezes, a gente fica meio desestruturado, mas não pode deixar as emoções transbordarem, se você desabar, pode acabar desestruturando o grupo e até mesmo a família. Às vezes, acham que a gente é frio, mas tem momentos que não podemos parar para ficar lamentando, porque tem outras crianças, então como proteção a gente faz tecnicamente, pois temos que estar fortes e ter equilibrio para lidar. Claro que não dá para dissociar tudo, não é por lacunas ou por caixas, pois a gente é uma coisa só. Em algumas situações, é difícil segurar a emoção, as mães choram e a gente chora junto, e assim a gente se apega àquilo que acredita. Eu acredito e confio em Deus, questiono, peço força e explicação a Ele, costumo também falar com pessoas próximas, colegas de trabalho ou em casa. Logo depois do óbito vem um silêncio muito grande, mas sempre tem um momentinho que a gente compartilha o sentimento para a superação dos medos, das frustrações e de tudo o que a gente vivencia na UTI. Essas situações de terminalidade acabam sendo também um aprendizado para a equipe, fortalece a forma de atuar, ver onde errou e crescer como profissional. Mas, apesar da gente conversar, quando saio procuro deixar aqui, no começo era mais difícil, sempre é uma sensação de angústia, mas a gente vai aprendendo a administrar, por isso, acredito que, a cada situação 
vivenciada, a gente coloca um tijolinho de resiliência, vai construindo e ficando mais forte. (DSC 3)

\section{Discussão}

A partir do DSC 1, pode-se observar que aceitar a terminalidade da criança é um desafio complexo à equipe de enfermagem, que se vê diante de situações consideradas não naturais, pois existe uma expectativa de futuro para a criança, suscitando sentimentos e sensações angustiantes. Tais sentimentos são explicados a partir de uma expectativa social de que esses profissionais sejam mantenedores da vida e o não cumprimento dessa responsabilidade faz emergir tais emoções. Evidencia-se, ainda, que a possibilidade de morte da criança, apesar de ser um evento possível a todos os seres vivos, é rejeitada e quando a realidade se torna iminente o sofrimento se amplia. ${ }^{9-10}$

O sentimento de impotência se justifica devido à incapacidade de interromper o processo de terminalidade e impedir o óbito. Esse fato pode levar o profissional a contestar as medidas terapêuticas e até mesmo sua atuação, levando a repercussões psíquicas que causam estresse e ampliam o sofrimento gerado pelo processo de morte do paciente. ${ }^{5,10}$

Outros sentimentos são vivenciados, como os relatados em estudo, ${ }^{11}$ no qual se expõe que, em determinados momentos, a equipe pode desfrutar também de sentimentos bons, como a gratificação, a valorização e a realização, quando vê de alguma forma seu trabalho reconhecido pelo paciente e, principalmente, pela família. Para a equipe, a sensação de dever cumprido funciona como motivação para a realização do cuidado.

O cuidado paliativo pode ser entendido como o momento em que se esgotam as possibilidades terapêuticas e o paciente não responde mais ao tratamento curativo. No entanto, a sociedade ocidental associa a morte ao fim da vida, não a relacionando a um processo fisiológico natural, o que causa sensações de estranheza, angústias e tristeza. ${ }^{2}$ Assim, as enfermeiras entrevistadas, como relatado no DSC 1, demonstraram que possuem limitações em 
A resiliência do enfermeiro no cuidado à criança que vivencia a terminalidade $\mid 10$

aceitar o cuidado paliativo quando se trata da terminalidade, e por trabalharem na UTI e com público infantil sentem a responsabilidade de realizar medidas para manter a vida, independentemente do prognóstico.

Nesse sentido, pesquisas ${ }^{10,12}$ apontam que, no ambiente de terapia intensiva, frente ao aparato tecnológico que auxilia na manutenção da vida, a cura é buscada incessantemente, e para os profissionais, por vezes, é difícil compreender e aceitar a morte. Assim, a enfermeira que trabalha na UTI se vê entre sua responsabilidade técnica profissional e suas crenças, valores e sentimentos, dilemas que se tornam intensos quando se trata do cuidado à criança terminal.

Observou-se no DSC 1 que as enfermeiras relataram que o fato de serem mães faz com que o processo de aceitação da terminalidade infantil seja doloroso, e isso se justifica devido à projeção da fragilidade no outro e uma identificação com o doente, o que faz com que a finitude da criança traga à luz a possibilidade da perda do próprio filho. ${ }^{11}$ Contudo, na busca da literatura, percebeu-se que ainda são escassos os estudos que abordam o sofrimento de profissionais de saúde que são mães e trabalham com a terminalidade infantil.

Em vista disso, assistir a criança terminal requer do enfermeiro não somente a prestação de cuidados diretos ao paciente, mas o contexto social e familiar aos quais a criança está inserida também precisam ser considerados. Porém, todas essas vertentes de cuidados, a depender de como estão configuradas, podem interferir no emocional do profissional e no seu enfrentamento para com a terminalidade infantil. Diante desse cenário, a enfermeira passa a desenvolver empatia, se colocando no lugar da família e prestando-lhe, muitas vezes, suporte emocional.

Pode-se observar no DSC 2 que as enfermeiras relataram a importância da construção de vínculo com a família da criança que se encontra em estado terminal, e este envolvimento é considerado essencial para a efetivação de um cuidado humanizado. Nesse sentido, estudos trazem que o cuidar de crianças em situação de finitude exige que o profissional desenvolva 
determinadas características que contribuem para a formação de vínculo e confiança com o paciente e a família, para assim promover conforto..$^{3-4,13}$

Conforme discorrido pelas enfermeiras entrevistadas, no DSC 2, o envolvimento com a história de vida da criança e de sua família faz com que elas assumam uma postura empática para o cuidado, buscando compreender como o processo de terminalidade afeta os envolvidos. Tal atitude, segundo elas, faz com que adotem uma postura sensível, acolhedora e humanizada. Nesse contexto, a empatia do cuidador com o ser cuidado é essencial, pois se imaginar no lugar do outro e vivenciar sua dor favorece a realização de um cuidado sensível, em que a comunicação entre enfermeira e paciente é valorizada. ${ }^{3-4}$

Quando a enfermeira pratica uma assistência empática, ela considera a família como parte indissociável para o cuidado ao paciente que vivencia a terminalidade. Nesse âmbito, a família é compreendida como uma estrutura em que todos os seus membros estão interligados, e quando um deles adoece toda a atenção se volta ao enfermo, suscitando sentimentos angustiantes. Devido à maior proximidade, a enfermagem é a profissão que se mostra mais acessível e, portanto, se torna um apoio para o familiar por acompanhar de perto suas preocupações, inquietações e angústias. ${ }^{4}$

O diálogo, a escuta, a compreensão das necessidades prioritárias, não só físicas, mas também as de caráter subjetivo, por meio do apoio e suporte emocional para o enfrentamento da terminalidade, faz com que a enfermeira se envolva emocionalmente com a criança no fim da vida e com sua família, desta forma, se aproximando do sofrimento vivenciado por elas. Esse cuidado propicia o exercício da sensibilidade na assistência; porém, faz-se necessário estabelecer limites afetivos, a fim de evitar posteriores problemas emocionais ao profissional, pois percebe-se que, com a formação de vínculos e envolvimento, mais difícil é a aceitação da terminalidade. ${ }^{14}$

Quando se propõe um trabalho humanizado, os sentimentos precisam ser levados em consideração, tanto do paciente quanto do profissional que o assiste. ${ }^{4}$ Outras pesquisas, que 
A resiliência do enfermeiro no cuidado à criança que vivencia a terminalidade $\mid 12$

tratam sobre a morte na perspectiva dos profissionais de saúde, ${ }^{1,15}$ acrescentam que é importante considerar a tristeza ou até mesmo a manifestação do choro diante do óbito de um paciente, reconhecendo-se, assim, a humanidade existente no profissional. Porém, reitera-se que a expressão de sentimentos deve ser comedida, de modo que não prejudique a assistência prestada e as relações interpessoais.

O cuidado humanizado torna a vivência da finitude menos traumatizante, tanto para o profissional quanto para a família. A execução de um cuidado sensível favorece o desenvolvimento de empatia, compaixão e apego com a criança e a família, e preza pela oferta de conforto como forma de tornar esse momento o mais suave possível. ${ }^{16}$

Mesmo no ambiente da UTI, onde há o predomínio de um modelo de assistência voltado para tecnologias, com a necessidade de uso de uma diversidade de equipamentos (monitores, ventiladores mecânicos, máquinas de hemodiálise, dentre outros), atualmente já se reconhece que a humanização é peça fundamental de cuidado, principalmente quando se trata da terminalidade. Nesse sentido, acrescer uma visão ampliada da assistência à criança terminal não se resume a estimular a destreza e o conhecimento científico, mas, além disso, considerar os aspectos psicossocial e espiritual que envolvem o cuidado. ${ }^{15}$

Ao agir com empatia, a enfermeira torna a sua prática assistencial mais humanizada e consegue se aproximar do objetivo do cuidado no fim da vida, promovendo o conforto e bemestar de forma integral. A implementação de uma assistência dessa natureza favorece não somente a criança terminal, mas todos os envolvidos no contexto de morte.

Muitos profissionais encaram a terminalidade infantil também como uma oportunidade de crescimento pessoal e profissional. Para isso, é necessário o desenvolvimento de estratégias para o enfrentamento e construção da resiliência. Dentre as estratégias apontadas, a fé e a religião se mostraram evidentes, além do apoio emocional prestado pelos colegas de trabalho. 
O DSC 3 traz no relato das entrevistadas a forma como elas constroem a resiliência para lidar com a terminalidade infantil. Essa situação exige do profissional equilíbrio emocional, desenvolvimento de uma capacidade de superação e de adaptação às adversidades, para isso a construção de uma postura resiliente é fundamental. Desse modo, a enfermeira desenvolve estratégias para se fortalecer, enfrentar o sofrimento e favorecer seu desenvolvimento. ${ }^{17}$

Os enfermeiros passam a maior parte do tempo na assistência à criança e seu grupo familiar, por isso é necessário que desenvolvam habilidades para cuidar não só das necessidades físicas, mas psicológicas e espirituais da criança e sua família. ${ }^{18}$ As estratégias para enfrentamento podem variar desde medidas de afastamento até um forte acolhimento, de modo que cada profissional se utiliza de mecanismos baseados em sua própria experiência. ${ }^{6}$

A resiliência pode ser aprendida, desenvolvida e moldada; pode ser uma característica individual, mas também influenciada pelo coletivo, a depender do quanto aquele indivíduo se reconhece como parte de um grupo. Essa sensação de acolhimento e pertencimento contribui para que o profissional encontre apoio para a construção da resiliência. ${ }^{17}$

Em geral, as instituições hospitalares requerem dos seus trabalhadores racionalidade e produtividade, ${ }^{5}$ características que impõem limitações aos indivíduos, que têm que separar o seu lado profissional do pessoal. Isso é corroborado no discurso das entrevistadas, no DSC 3, em que afirmam não poder se lamentar, pois necessitam estar bem para assistir as outras crianças.

A fim de minimizar os impactos causados no enfrentamento da terminalidade infantil, por meio de orações e pensamentos positivos, muitos buscam no âmbito espiritual e na fé o auxílio necessário para manter a esperança, com o propósito de proporcionar cuidado e conforto para seus pacientes. Outros optam pela individualização do sofrimento, no entanto isso geralmente provoca uma sobrecarga emocional. Nesse sentido, compreender esse processo e conversar sobre suas angústias faz com que o profissional tenha voz, seja ativo e lide melhor 
A resiliência do enfermeiro no cuidado à criança que vivencia a terminalidade | 14

com as intempéries do trabalho. Desse modo, o trabalho em equipe é essencial não somente para a assistência, mas também para fornecer apoio e suporte emocional entre seus membros. ${ }^{3,5}$

Como observado no DSC 3, vivenciar situações de terminalidade pode também ser produtivo para a equipe, pois permite reflexão quanto à assistência prestada, o que corrobora os achados de outra pesquisa, que analisou como a equipe de enfermagem de UTI Pediátrica lida com o processo de morte. $^{19}$ Isso propicia o aprendizado não apenas em relação ao desenvolvimento técnico, mas também no que concerne a questões subjetivas, como o desenvolvimento de habilidades em resolução de problemas, além do lidar com os familiares, e aos aspectos éticos, a fim de desenvolver uma assistência de qualidade. ${ }^{16,20}$

Nesse contexto, há a necessidade de criar estratégias, na forma de educação continuada, para que os profissionais possam expressar seus sentimentos e enfrentar seus dilemas, principalmente os relacionados à assistência e às questões que envolvem a terminalidade. ${ }^{9}$ Dessa forma, é necessário refletir sobre o processo de trabalho, recuperando a compreensão de que a morte é um fenômeno natural que, inevitavelmente, faz parte da vida, para que o sofrimento psíquico seja minimizado e haja melhoria na qualidade de vida dos profissionais. ${ }^{15}$

Estudo $^{21}$ que avaliou a resiliência de trabalhadores de enfermagem com atuação hospitalar, em vários setores, inclusive a pediatria, reitera que a resiliência não é permanente e sim um estado, visto que as situações são mutáveis e a resposta a elas também é dinâmica. Portanto, a resiliência é aprimorada a cada circunstância vivenciada. A pesquisa revela ainda a importância da identificação e tratamento de sofrimento mental relacionado ao trabalho, para que a aflição não seja prejudicial à atuação profissional.

Para a construção da resiliência, a enfermeira necessita identificar as suas fontes de apoio, seja no âmbito espiritual ou por meio do suporte fornecido por colegas de trabalho ou até mesmo por profissionais especializados em saúde mental. O devido suporte auxilia o 
15 | Andrade BRV, Cunha JXP, Biondo CS

profissional a identificar suas limitações, desenvolver o autocuidado e autogerenciar suas emoções, para o cuidado à criança terminal.

Observou-se como limitações da pesquisa a visualização de uma única realidade, por se tratar de estudo local em um município. Além disso, a maioria das entrevistas ocorreu em Unidades de Terapia Intensiva Neonatal, fato que pode não ter explicitado a realidade das unidades pediátricas.

\section{Conclusão}

A terminalidade infantil produz nas participantes do presente estudo sentimentos de angústia, tristeza e impotência. Percebeu-se também que a equipe de enfermagem possui preparo emocional insuficiente para lidar com a finitude da vida infantil, não aceitando a morte da criança terminal. Neste estudo, observou-se que o sofrimento das enfermeiras se amplia quando elas possuem filhos, porém existe uma necessidade de que outros estudos sejam realizados para reforçar o entendimento de como as profissionais de saúde que são mães lidam com o sofrimento gerado pela morte da criança no ambiente de trabalho.

A análise dos resultados demonstrou também que a empatia é essencial para que o cuidado prestado à criança terminal seja humanizado e que este se dá, muitas vezes, a partir do envolvimento emocional com a criança e sua família. É notório que, apesar da necessidade de uma assistência sensível, se deve estabelecer equilíbrio e limites afetivos, a fim de minimizar o sofrimento profissional.

A construção da resiliência foi descrita como algo que se encontra em constante transformação e que é moldada a cada situação vivenciada. Como estratégias pessoais para a produção da resiliência, as entrevistadas referem o exercício da espiritualidade, além do diálogo para expressar suas inseguranças e angústias. 
A resiliência do enfermeiro no cuidado à criança que vivencia a terminalidade | 16

Por fim, faz-se necessário que a finitude seja enfrentada como curso natural da vida. Para tal, as instituições de ensino e laborais devem investir em discussões sobre a terminalidade, a fim de que enfermeiros(as) descubram mecanismos de enfrentamento e de construção da resiliência para o cuidado à criança que se encontra no fim da vida.

\section{Referências}

1. Costa DT, Garcia LF, Goldim JR. Morrer e morte na perspectiva de residentes multiprofissionais em hospital universitário. Rev Bioét. 2017;25(3):544-53. doi: 10.1590/1983-80422017253211

2. Santana JCB, Pessini L, Sá AC. Vivências de profissionais da saúde frente ao cuidado de pacientes terminais. Enferm Rev [Internet]. 2017 [acesso em 2020 set 02]:20(1):1-12. Disponível em: http://periodicos.pucminas.br/index.php/enfermagemrevista/article/view/15410

3. Santos RA, Moreira MCN. Resiliência e morte: o profissional de enfermagem frente ao cuidado de crianças e adolescentes no processo de finitude da vida. Ciênc Saúde Colet. 2014 dez;19(12):4869-78. doi: 10.1590/1413-812320141912.18862013

4. Lima PC, Comassetto I, Faro ACM, Magalhães APN, Monteiro VGN, Silva PSG. O ser enfermeiro de uma central de quimioterapia frente à morte do paciente oncológico. Esc Anna Nery. 2014 jul;18(3):503-9. doi: $10.5935 / 1414-8145.20140071$

5. Bastos RA, Quintana AM, Carnevale F. Angústias psicológicas vivenciadas por enfermeiros no trabalho com pacientes em processo de morte: estudo clínico-qualitativo. Trends Psychol. 2018 jun;26(2):795-805. doi: 10.9788/TP2018.2-10Pt

6. Henao-Castaño ÁM, Quiñonez-Mora MA. Afrontamiento de las enfermeras ante la muerte del paciente en la Unidad de Cuidado Intensivo Pediátrico. Enferm Intensiva. 2018 oct;30(4):163-9. doi: 10.1016/j.enfi.2018.10.005

7. Polit DF, Beck CT. Fundamentos da pesquisa em enfermagem: avaliação de evidências para a prática em enfermagem. 9ª ed. Porto Alegre: Artmed; 2018.

8. Lefevre F, Lefevre AMC. Discurso do sujeito coletivo: representações sociais e intervenções comunicativas. Texto Contexto Enferm. 2014;23(2):502-7. doi: 10.1590/0104-07072014000000014

9. Scaratti M, Oliveira DR, Rós ACR, Debon R, Baldissera C. Do diagnóstico a terminalidade: enfrentamento da equipe multiprofissional na oncologia pediátrica. Rev Pesq Cuid Fundam [Internet]. 2019 jan [acesso em 2019 jun 14];11(N Esp):311-6. Disponível em: http://www.seer.unirio.br/index.php/cuidadofundamental/article/viewFile/6464/pdf_1 
10. Sartori AV, Battistel ALHT. A abordagem da morte na formação de profissionais e acadêmicos da enfermagem, medicina e terapia ocupacional. Cad Bras Ter Ocup. 2017;25(3):497-508. doi: 10.4322/25268910.ctoAO0770

11. Santos MA, Hormanez M. Atitude frente à morte em profissionais e estudantes de enfermagem: revisão da produção científica da última década. Ciênc Saúde Colet. 2013;18(9):2757-68. doi: 10.1590/S1413-81232013000900031

12. Rocha DD, Nascimento EC, Raimundo LP, Damasceno AMB, Bondim HFFB. Sentimentos vivenciados pelos profissionais de Enfermagem diante de morte em unidade de terapia intensiva neonatal. Mental [Internet]. 2017 jul-dez [acesso em 2019 jun 14];11(21):546-60. Disponível em: http://pepsic.bvsalud.org/scielo.php?script=sci_arttext\&pid=S1679-44272017000200015

13. Souza L, Vinotti J, Maximo S. O impacto emocional da relação entre a equipe de enfermagem e bebês internados na utineo e seus familiares. Rev Interdiscip Estud Saúde [Internet]. 2017 ago [acesso em 2020 set 04];6(1):213-33. Disponível em: http://periodicos.uniarp.edu.br/index.php/ries/article/view/969

14. Silva TP, Silva MM, Alcantara LM, Silva IR, Leite JL. Estabelecendo estratégias de ação/interação para o cuidado à criança com condição crônica hospitalizada. Esc Anna Nery. 2015;19(2): 279-85. doi: $10.5935 / 1414-8145.20150037$

15. Vicensi MC. Reflexão sobre a morte e o morrer na UTI: a perspectiva do profissional. Rev Bioét. 2016;24(1):64-72. doi: 10.1590/1983-80422016241107

16. Silva CMM, Silva MPC, Ferreira DO, Amaral JB, Gonçalves JRL, Contim D. Significado do cuidar e seus sentimentos para equipe de enfermagem diante da criança em tratamento oncológico. Rev Enferm Atenção Saúde. 2018;7(2):83-94. doi: 10.18554/reas.v7i2.2355

17. Cruz EJER, Souza NVDO, Amorim LKA, Pires AS, Gonçalves FGA, Cunha LP. Resiliência como objeto de estudo da saúde do trabalhador: uma revisão narrativa. Rev Pesq Cuid Fundam. 2018;10(1):2838. doi: 10.9789/2175-5361.2018.v10i1.283-288

18. Cole MA, Foito K. Pediatric end-of-life simulation: preparing the future nurse to care for the needs of the child and family. J Pediatr Nurs. 2018 Sept;44:9-12. doi: 10.1016/j.pedn.2018.09.005

19. Souza PSN, Conceição AOF. Processo de morrer em unidade de terapia intensiva pediátrica. Rev Bioét. 2018;26(1):127-34. doi: 10.1590/1983-80422018261234.

20. Muskat B, Greenblatt A, Anthony S, Beaune L, Hubley P, Newman C, et al. The experiences of physicians, nurses, and social workers providing end-of-life care in a pediatric acute-care hospital. Death Stud. 2019;44(2):105-16. doi: 10.1080/07481187.2018.1526829

21. Silva SM, Baptista PCP, Silva FJ, Almeida MCS, Soares RAQ. Fatores relacionados à resiliência em trabalhadores de enfermagem no contexto hospitalar. Rev Esc Enferm USP. 2020;54:e03550. doi: 
$10.1590 /$ S1980-220X2018041003550

\section{Editora Científica Chefe}

Cristiane Cardoso de Paula

\section{Editora associada}

Alexa Pupiara Flores Coelho

\section{Autor correspondente}

Juliana Xavier Pinheiro da Cunha

E-mail: julianaxcunha@gmail.com

Endereço: Rua Hormindo Barros, 58, Quadra 17, Lote 58, Gabinete 313. Bairro Candeias

CEP: 45.029-094

\section{Contribuições de Autoria}

1 - Bruna Raiane Viana Andrade

Concepção ou desenho do estudo/pesquisa, análise e/ou interpretação dos dados, revisão final com participação crítica e intelectual no manuscrito.

\section{2 - Juliana Xavier Pinheiro da Cunha}

Concepção ou desenho do estudo/pesquisa, análise e/ou interpretação dos dados, revisão final com participação crítica e intelectual no manuscrito.

\section{3 - Chrisne Santana Biondo}

Revisão final com participação crítica e intelectual no manuscrito

\section{Como citar este artigo}

Andrade BRV, Cunha JXP, Biondo CS. A resiliência do enfermeiro no cuidado à criança que vivencia a terminalidade. Rev. Enferm. UFSM. 2020 [Acesso em: Anos Mês Dia]; vol.10 e88: 1-18. DOI:https://doi.org/10.5902/2179769240348 